\title{
El lenguaje y la ficción encarnada. Un acercamiento fenomenológico a Cuento amarillo.
}

Language and embodied fiction. A phenomenological approach to Cuento amarillo.

DOI: 10.32870/sincronia.axxv.n79.12a21

\author{
Joselyn Pérez Pérez
}

Universidad Ibero. Campus Santa Fe (MÉXICO)

CE: joselynperezperez@gmail.com / ID ORCID: 0000-0002-7224-5395

\section{Esta obra está bajo una Licencia Creative Commons Atribución-NoComercial 4.0 Internacional}

Recibido: $13 / 07 / 2020$

Revisado: 03/10/2020

Aprobado: $19 / 11 / 2020$

\section{RESUMEN}

Este artículo es un acercamiento literario que busca dar respuesta a la pregunta sobre la relación fenomenológica entre cuerpo-lenguaje en el cuentario Cuento amarillo. Para ello utiliza como base teórico la fenomenología de Merleau-Ponty en dos obras base La prosa del mundo y La fenomenología de la percepción a partir de las cuales se busca explorar como los conceptos de cuerpo, lenguaje y ficción están operando dentro de la narrativa de esta obra con la finalidad de vislubrar las directrices textuales que configuran a los personajes y así crear una propuesta nueva hacia el cuerpo con vistas a una discusión teórica con el lenguaje.

Palabras Clave: Fenomenología. Cuerpo. Lenguaje. Literatura. Ficción. Cuento.

\section{ABSTRACT}

This article is a literary approach that seeks to answer the question about the phenomenological relationship between body-language and the storyteller Cuento amarillo. For this, he uses the Merleau-Ponty phenomenology as a theoretical base in two base works, The Prose of the World and The Phenomenology of Perception, from which he seeks to explore how the concepts of body, language and fiction are operating within the narrative with the purpose is to glimpse the textual guidelines that make up the characters of this literary work and within phenomenology itself and therefore create a new proposal towards the body with a view to a theoretical discussion with language. 
Keywords: Phenomenology. Body. Language. Literatura. Fiction. Story.

El acercamiento literario al cuerpo implica una discusión teórica con el lenguaje. Es indisoluble la relación tripartita que estos constructos teóricos proponen. Ello implica abrir la discusión indagatoria hacia la pregunta sobre qué es el cuerpo, qué es el lenguaje y cómo se vincula con el plano de lo literario. El objetivo de este artículo radica en explorar estos vasos comunicantes dentro del espacio ficcional que propone el texto Cuento amarillo. Para ello, es necesario tomar como punto de partida y basamento teórico la propuesta fenomenológica de Merleau-Ponty cuya exploración involucra interrogantes sobre la percepción, el cuerpo-vivido, el cuerpo-experimentado y sus interconexiones al terreno de lo literario. En este tenor, es posible plantear a modo de pregunta de investigación ¿cuál es la relación fenomenológica entre cuerpo-lenguaje y el cuentario Cuento amarillo?

\section{El cuerpo de Adriana Conde y “Ácido"}

Merleau-Ponty propone al cuerpo como medio por el cual el mundo se experimenta, no es una simple constitución mecánica, biológica inexpresiva, sino su cualidad es que a través de él se vivencia y conoce el mundo. Ahora bien, para ello es necesario comprender la inherencia del cuerpo respecto la realidad. Es decir, saber que el cuerpo es una experiencia encarnada en la conciencia. Experimentar la realidad es un acto consciente cuya posibilidad de ser es por el cuerpo:

[..] el cuerpo no es un objeto transparente y no nos es dado como lo es el círculo al geómetra, por su ley de constitución; si es una unidad expresiva que uno sólo puede aprender a conocer asumiéndola, esta estructura se comunicará al mundo sensible. La teoría del esquema corpóreo es implícitamente una teoría de la percepción. Hemos aprendido de nuevo a sentir nuestro cuerpo, hemos reencontrado bajo el saber objetivo y distante del cuerpo este otro saber que del mismo tenemos, porque está siempre con nosotros y porque somos cuerpo. De igual manera será preciso despertar la experiencia del mundo tal como se nos aparece en cuanto somos del-mundo por nuestro cuerpo, en cuanto percibimos el 
mundo con nuestro cuerpo. Pero al tomar así nuevo contacto con el cuerpo y el mundo, también nos volveremos a encontrar a nosotros mismos, puesto que, si percibimos con nuestro cuerpo, el cuerpo es un yo natural y como el sujeto de la percepción. (MerleauPonty, 1993).

El cuerpo para Merleau-Ponty no es un recipiente vacío, no es solo un ente, sino vínculo para el mundo; en ese sentido, el cuerpo contiene para así una categoría cognitiva y sensitiva. La relación que se establece entre hombre y realidad está determinada por el cuerpo, es espacio que se va construyendo por los sentidos. La experiencia del mundo tal como se conoce es por el cuerpo esto permite concluir dos puntos: primero el cuerpo es un "yo natural" y dos comprender "al sujeto como percepción".

De acuerdo con lo anterior, es pensar también que la idea del cuerpo no es clara, sino que entre mezcla de manera implícita en un pensamiento que siempre es otra cosa de lo que realmente es; es decir, el concepto del cuerpo se construye a través de la percepción de sí mismo, la forma de concebir el cuerpo deviene de la experiencia de vivirlo; se conocen nociones de sexualidad, libertad porque se vivencia en la naturaleza del cuerpo y de su percepción. La unión sujeto-cuerpo conlleva implícitamente la imposibilidad de separarlo como un objeto. El cuerpo no es otro ajeno al sujeto, sino el sujeto es el cuerpo y éste a su vez crea una realidad que se inserta o penetra en el mundo.

En sentido, al comenzar explorar la construcción de cuerpo en Cuento amarillo es posible vislumbrar que la realidad ficcional proyectada solo es posible porque el cuerpo no está ajeno al sujeto de la percepción; es decir, la protagonista que aparece en los tres cuentos Adriana Conde, construye mundos bajo la concepción de sujeto-cuerpo es una totalidad de la realidad de uno de sus tantos mundos y dice la narradora:

Con la aparición del cuaderno rojo me vino una extraña condición: sólo era capaz de escribir el principio de las historias. Después mis dedos no querían moverse. Había ocasiones en que sólo anotaba frases sin sentido que no me hacían llegar a ningún lado. Las oraciones me las dictaba aquella que me visitó en el bosque. "El tiempo terminará", garabateaba poseída (Rendón, 2020). 
Adriana Conde es una escritora, como tal su ejercicio de creación es constante, sin embargo, solo es posible si el cuerpo le da permiso. Comienza en ella la vivencia de su espacio ficcional a través de la imposibilidad de escribir. Aparece un artefacto: un cuaderno rojo; objeto que en sí mismo condiciona al cuerpo, o, dicho de otra manera, la percepción del sujeto, en este caso Adriana Conde en relación con este cuaderno rojo se vivencia por el cuerpo. En este caso, el resultado de esta relación es la imposibilidad corpórea por escribir. De esta manera, se vislumbra al sujeto-cuerpo como una totalidad. No solo basta con que Adriana Conde quiera crear ficciones, sin el cuerpo ella no podrá hacerlo, su quehacer escritural es un binomio con su propio cuerpo.

Ello invita a reflexionar que la experiencia humana construye sentido en el momento en que se conectan las percepciones del pensamiento racional con el de los sentidos corpóreos, ello posibilita la aprehensión del mundo. A partir de este marco de referencia es posible decir que el pensamiento y la experiencia están posibilitadas por la medialidad del cuerpo. En "Ácido" la percepción del sujeto va en aumento cada vez que Adriana Conde comienza a consumir drogas, mismas que van desde la mariguana, el ácido, la cocaína o bien el cigarro. Este ejercicio en donde este personaje busca constantemente estados alterados de la consciencia también impacta en el cuerpo. Las sensaciones irán in creciendo y por la tanto es posible que se establezcan grados de aprehensión del mundo de formas varias, tantas como sea posible para que esta escritora se habilite para crear múltiples universos ficcionales, nuevas espacialidades y nuevas temporalidades y dice Adriana Conde:

Su asistente tenía la cualidad de mimetizarse con el espacio. Por momentos estaba segura que sólo estábamos él, Polvorilla y yo. Después de escuchar mis aspiraciones literarias me ordenó quitarme el vestido y recostarme sobre su escritorio, que estaba en una pequeña habitación junto a la sala. La luna roja le proporcionaba a la situación un aire de sueño mórbido. -Nunca mi escritorio se ha visto más hermoso que con tu presencia -dijo Juan con la voz de su asistente. Me ruboricé y tuve la sensación de alejarme completamente del lugar. El infierno recorrió mis vísceras. Polvorilla se subió al escritorio y se recostó en la curva entre mi cadera y mis pechos y se volvió verde. Todo estaba en silencio. Tenía la urgencia de una 
raya de coca y le dije a la mulata "Pásame mi bolsa". Juan asintió con la mirada y la morena me la acercó. Aspiré el polvo de la curva que hacía mi dedo pulgar. Juan me recorría con sus ojos. -Juan quiere lamerte un pezón -dijo la morena. Me quedé un largo rato en silencio. La coca estaba haciendo efecto: un calor sexual me comenzó a invadir. (Rendón, 2020)

El contacto y la relación que entabla Adriana Conde con García Ponce se convierte además de un rito de iniciación para convertirse en escritora, aunado a esto es también un acto en donde la construcción de estos mundos solo será posible, al menos en el cuento de "Ácido", a través de la alteridad a la percepción vivenciada únicamente por las sensaciones del cuerpo.

El juego de estas sensaciones corpóreas motivadas por las drogas comienza a ligarse la sexualidad de Adriana Conde como un acto liberador creativo, por un lado, pero también, por el otro, le permiten a este personaje una movilidad espacio-temporal que modifica su mundo y su ficción y dice el texto nuevamente:

Comencé a forjar el cigarrillo de marihuana para compartirlo con Alfonso. Me di cuenta más tarde que todo su estudio estaba tapizado de bachas. El ambiente se tiñó de tristeza. Lo miré fijamente y me pidió que me quitara la ropa, obedecí. Una vez desnuda ingerí un éxtasis. Arias hizo lo mismo, se desnudó y sacó la lengua para que le metiera la droga. Me ordenó que me introdujera en la alberca. No quise y me empujó con violencia al agua: comenzó a ahogarme al tiempo que intentaba cortarme la mano con el tatuaje de ojo. De pronto me encontré vagando por un callejón de Coyoacán. Mujeres y hombres caminaban a mí alrededor poseídos. Arias me agarró de la mano y me mostró un edificio rojizo en cuya entrada se podía leer: Familia Macías Conde. "Julián Macías es el escritor divorciado que vi en el Caras", pensé. El agua de la alberca estaba por llenar mis pulmones, cerré los ojos y al abrirlos me encontré en la banqueta frente al Palacio de Minería. Una multitud de personas me observaba. Mi playera estaba cubierta de mi propia saliva. Mi entrepierna húmeda me provocó arcadas y el olor fétido de mis calzones inundaba el ambiente. Salí huyendo del lugar (Rendón, 2020). 
En una primera imagen Adriana Conde, después de su encuentro con García Ponce, se encuentra en el Palacio de Minería intentando tener una cita con otro escritor Julián Macías, a la espera de verlo, ella comienza a fumar un cigarro de marihuana. Al estar con Julián el acto sexual comienza y las sensaciones corpóreas se manifiestan por el efecto del cigarrillo de mota, acto seguido ella es arrojada al agua, pareciera que se ahoga, la percepción del cuerpo se intensifica y en un momento álgido ella aparece nuevamente en Coyoacán sola ¿qué sucedió? En términos de Merleau-Ponty sería:

La percepción, como fenómeno incorporado, es el ámbito donde los sentidos se conectan e implica una noción amplia acerca de las concepciones de pensamiento y conocimiento que en la tradición moderna corresponde a la razón y la objetividad. Por tanto, la conciencia reflexiva, la aprehensión del mundo por medio de la idea no posibilita el fundamento de la experiencia, sino la conciencia corporal que abarca el conocer, sentir, pensar imaginar (Merleau-Ponty, 1993)

La percepción corporal en tanto que es aprehensión del mundo conlleva comprender la conciencia del cuerpo pues ésta es una entidad totalizadora que consume y consolida para sí actos de pensamiento, imaginación y conocimientos y justo estos tres elementos son los que envuelven a Adriana Conde en "Ácido" cuando consume drogas e intenta escribir, es gracias a ellas que se traslada entre realidades y las altera, sin importar que sean parte del "viaje" o de la alucinación provocada por las drogas, esta alteridad se transforma en real, es por ello que para Adriana Conde consumir estas sustancias es fundamental, porque al contacto con ellas, la conciencia corporal de la habla Merleau-Ponty cobra sentido. Las sustancias adictivas que provocan estos estados alterados de la consciencia en el cuerpo de Adriana Conde no es más que su propia capacidad para crear y por tal motivo es que puede pasar de un espacio a otro, de estar en una alberca ahogándose a Coyoacán.

El cuerpo de Adriana Conde es el eje creativo y como evidencia de estos movimientos espaciales están su saliva, la humedad en su entrepierna y los aromas fétidos que imana de su ropa 
interior. Es decir, esta imagen muestra que el cuerpo es el creador de su propia ficción. Por lo tanto, es posible afirmar que el cuerpo de este personaje es lenguaje.

\section{Cuerpo-lenguaje en “Cuento amarillo"}

Si se asume desde el primer cuento que es "Ácido" a Adriana Conde como un cuerpo creador de ficciones, entonces al llegar al texto final "Cuento Amarillo" esta corporeidad concreta la noción de lenguaje; es decir, la trama de esta última narración va a introducir un personaje aún más complejo que la propia Adriana, se crea en este universo un cuento-hombre que se va alimentar y desprender de la misma protagonista y cuya complejidad está unida al cuerpo-lenguaje, pero ¿qué implica esto último? Implica pensar que "el cuerpo-lenguaje constituye la experiencia ambigua de la existencia humana" (Pinzón, 2014).

Pensar en la ambigüedad involucra el ejercicio de reflexivo en torno al sujeto, en la medida en que éste crea y construye a partir de la percepción. Dado que la percepción es un ejercicio individual, la interpretación del mundo varia de persona a persona. Así, la existencia humana se crea por la polisemia del cuerpo, mismo que se transforma constantemente. Es decir, ningún cuerpo es igual, así sea el mismo anclado a un único sujeto, éste se configura y refigura por las propias experiencias. Entonces, si la ambigüedad es una polisemia del cuerpo y este es a su vez lenguaje, los ejercicios de aprehensión del mundo son tan múltiples y cambiantes como es la polisemia misma. Al respecto explica Merleau-Ponty

Ya se trate del cuerpo del otro o del mío propio, no dispongo de ningún otro medio de conocer el cuerpo humano más que el de vivirlo, eso es, recogerlo por mi cuenta como el drama que lo atraviesa y confundirme con él. Así, pues, soy mi cuerpo, por lo menos en toda la medida en que tengo un capital de experiencia y, recíprocamente, mi cuerpo es como un sujeto natural, como un bosquejo provisional de mi ser total. (Merleau-Ponty, 1993).

Con la consciencia del cuerpo junto con el capital de experiencia que deviene de vivir, la percepción del mundo se convierte en una construcción de significados y semanticidades múltiples, amplias y 
cambiantes, las cuales varían de sujeto a sujeto. Así pues, el cuerpo se es un bosquejo de la totalidad del ser. La naturaleza de la ambigüedad es una forma más de creación, en este sentido, el cuerpo se convierte en lenguaje dado que es una expresión de las formas de percibir, y en este ejercicio, el mundo se convierte en una unidad abierta, es inacabado con un sentido diverso.

Si se lleva esta reflexión al campo de la ficción que crea Adriana Conde el lenguaje-cuerpo cobra vida con su personaje nacido de ella misma que es un cuento-hombre y la percepción del mundo se convierte aún más ambigua, abierta y polisémica. La ficción que se construye en "Cuento Amarillo" no es una realidad objetiva ni un sistema de significados finitos, acabados; sino se convierten en la anunciación de un nuevo sentido, esto se ejemplifica en el siguiente fragmento:

Ya tengo piel en casi todo el cuerpo: la Conde está trabajando horas extra, estoy casi terminado. Al mismo tiempo amplío mi vocabulario y hasta tengo la impresión de ser más inteligente. El capricho sexual es ahora mi prioridad. Construyo una mujer de las partes de muchas. Es la idea de una chiquita preciosa, sólo una, con muchos rostros. Vivo con ella, y por la mañana tiene un rostro, y por la noche tiene otro; después de bañarse uno diferente. Le cambian, al mismo tiempo, partes del cuerpo; partes del alma (Rendón, 2020)

Del mundo de Adriana Conde comienza a crecer una nueva criatura, al principio es un ajolote, después muta y es un objeto amorfo de mental y finalmente sufre una metamorfosis hasta llegar a ser un hombre, pero este hombre no un amante ordinario o un personaje ornamental del mundo de cuentos de Adriana Conde, por el contrario, es un cuento hecho hombre, pero además es el lenguaje convertido en hombre, ilustra la cita y justo cuando el cuerpo está terminando es que este personaje, este lenguaje-cuento-hombre podrá crear más allá de los mundos infinitos de Adriana y dice nuevamente:

El cuento, al final, lo invadió todo. Yo, después de él, ya no tengo nada. He vaciado todos mis cuadernos para complacerlo. A este cuento le he ofrendado todas mis historias, las escondidas durante muchos años. Me alegro, sin embargo, de haber quemado muchos de mis textos. También tengo bajo llave todos los borradores de esta historia son tres, uno está perdido. (Rendón, 2020) 
El cuento crece porque su cuerpo crece, se consolida en una forma cada vez más humana y esto solo es posible porque va adquiriendo al lenguaje; así de manera paralela y simbiótica entre mayor sea el lenguaje, mayor será la forma humana, la percepción abierta del mundo será cada vez más diversa, más expansiva ¿qué pasa con la protagonista? Será invadida y modificada en la totalidad del cuento-hombre, porque este personaje no es más que el lenguaje escondido en una forma humana, ¿por qué? Porque solo por el cuerpo es posible la percepción de lo real y el capital de la experiencia necesita a su vez un vehículo para mediarlo; esto es la necesidad del lenguaje. Es decir:

[...] la percepción del cuerpo y del lenguaje como fenómeno de entrelazamiento recíproco, tanto de significaciones instituidas como de significaciones en estado de nacimiento, de experiencias de hechos pasados acabados como de experiencias actuales, que hacen parte de nuestro presente inmediato. (Gamboa, 2014).

El cueto-hombre de Adriana Conde es devorador de sus mundos de ella misma porque al ser una forma del lenguaje posee inherentemente al pensamiento y a la palabra, ello implica:

La palabra es. la realización del pensamiento; pero esta realización se produce, debido a que en la palabra existe otra significación que es justa mente la base o el fundamento de la significación conceptual. Es decir, la palabra encierra una doble significación: una significación conceptual y una significación del gesto. Esta significación del gesto es denominada también "significación existencial" y es inseparable de las palabras (Estévez, 1980).

En la medida en que este cuento-hombre toma consciencia de su existencia y de su cuerpo y con él su capacidad de nombrar, entonces deviene el pensamiento, el cual es anterior al lenguaje; sin embargo, para que el pensamiento tenga una permanencia exige la expresión lingüística, la palabra es llamada porque es materialidad de él. El cuento-hombre de Adriana Conde no solo le basta con pensar, sino necesita a la palabra y cuando la posee, cuando la contiene y la arropa; es tan estrecho este entrelazamiento con este personaje que, al poseerla, ésta escapa de su cuerpo y lo invade todo 
y por lo tanto es capaz de reescribir a su creadora. La palabra adquiere una entidad y una vida propia la cual está personificada en el cuento- hombre.

El cuento me tiene aquí sentada sin poder moverme. Cuando él llegue todo se solucionará. Le quitará al cuento el cuaderno rojo y por fin podré regresar a la normalidad. Por lo pronto, hago estas anotaciones mentales. Las aprenderé de memoria y las repetiré una y otra vez, por si él no regresara. Es posible lograr salir de la prisión del cuento si después de un rato se convierte en recuerdo esta situación. Por fortuna el cuento me libera de la prisión estática, pero él no regresa a la casa. El cuento y yo discutimos varias horas y acepta escribir en el cuaderno rojo sólo cosas sin efecto en nuestra intimidad. A cambio yo lo dejo caminar una vez entre los otros vivos. Podrá llevar una libreta para anotar sus impresiones, pero borrará todo cuando esté en el umbral de la casa. Es sumamente arriesgado dejarlo salir. Quizá comience a modificarlo todo. Por eso he decidido darle una libreta espejo, todo lo escrito en ella será inmediatamente reescrito en otra libreta gemela que yo tengo. (Rendón, 2020)

El cuento-hombre se convierte en lenguaje en una dimensión esencial para él porque es capaz de expresar su vida y su relación con el mundo en conjuntos verbalizados. Así pues, este cuento se apropia de todo el mundo ficcional de "Cuento Amarillo", la escritura también se convierte en palabras vivas, habladas y estás afecciones simbolizan la realidad y el mundo, crean imágenes a la que sigue construyendo al cuento-hombre. A través del cuerpo, este personaje percibe y lo encarna en otros mundos, mismos que están por encima de la propia Adriana, y dice Merleau-Ponty:

He dado mi conocimiento de la lengua, he aportado lo que sabía sobre el sentido de estas palabras, de estas formas, de estas sintaxis (...). A favor de esos signos en los que el autor y yo hemos convenido, porque hablamos la misma lengua, me ha hecho creer que nos hallábamos en el terreno común de las significaciones adquiridas y disponibles. Se ha instalado en mi mundo. Y luego, insensiblemente, ha desviado los signos de su sentido ordinario, y helos aquí arrebatándome como un torbellino hacia ese otro sentido que voy a encontrar. (Merleau-Ponty, 1971) 
La tensión que crece y aumenta entre Adriana Conde y en el cuento-hombre es avasallador pues tiene la capacidad de crear nuevos mundos. Ambos se convierten en escritores de sus propias ficciones; y en donde ambos son los mismos personajes de estas creaciones, por lo tanto, estos desdoblamientos se tensionan. Los dos se convierten en continuidad y extensión de sus propias escrituras obligados a co-existir y al momento de imbricarse comienza una lucha corpórea de dominar al otro por el lenguaje. Ellos se reescriben, son unidades abiertas que se co-crean.

\section{Conclusiones}

En suma, acercase a Cuento amarillo desde la perspectiva de fenomenológica de Merleau-Ponty implica deconstruir la concepción de cuerpo, es una invitación a una reflexión teórica en donde la única forma de comprender estos movimientos entre las mini ficciones que se conjugan a lo largo de los tres cuentos implica la evocación a la sinestesia de los sentidos y modificas la manera en la que se entrelazan el cuerpo de los personajes con el mundo que cohabitan.

El cuerpo visto como lenguaje, así como lo apunta Merleau-Ponty permite dentro de la narrativa de Cuento Amarillo teorizar sobre la relación pensamiento-palabra-ficción dado que esta triada está personificada constantemente por el cuento-hombre y Adriana Conde, el control ambivalente entre uno y otro es porque se compiten categorías escriturales. Exigen transformaciones de reescrituras que solo son posibles cuando el cuento-hombre domina al cuerpo de Adriana Conde. Ambos son subconjuntos infinitos del lenguaje que se refiguran en la totalidad de los tres cuentos. Así, las apelaciones de los sentidos no están reducidos al espacio del texto, sino llegan a la lectura. Es decir, Cuento amarillo es también la deconstrucción del cuerpo de sus lectores. 


\section{Referencias}

Estévez, A. P. (1980). El lenguaje en Merleau-Ponty. Luz. Repositorio Académico, 132-152.

Gamboa, L. V. (2014). La experiencia corpora. La perecepción del lenguaje en Merleau-Ponty: apuntes para una fenomenología de la inter-culturalidad. Eidos, 260-282.

Merleau-Ponty. (1971). La prosa del mundo. Madrid: Tauros.

Merleau-Ponty, M. (1993). Fenomenología de la percepción. (J. Cabanes, Trad.) Barcelona, España: Planeta-Agostini.

Pinzón, H. J. (2014). La literatura como in-corporación: el cuerpo como proceso. La Palabra, 91-97. Rendón, L. (2020). Cuento Amarillo. CDMX: Cuadrivio. 